Article

\title{
Correlation of Influenza B Haemagglutination Inhibiton, Single-Radial Haemolysis and Pseudotype-Based Microneutralisation Assays for Immunogenicity Testing of Seasonal Vaccines
}

\author{
George W. Carnell ${ }^{1,+} \mathbb{D}$, Claudia M. Trombetta ${ }^{2}\left(\mathbb{D}\right.$, Francesca Ferrara ${ }^{1, \ddagger} \mathbb{D}$, Emanuele Montomoli ${ }^{2,3}$ \\ and Nigel J. Temperton $1, *$ (D)
}

1 Viral Pseudotype Unit, University of Kent and Greenwich, Chatham Maritime ME4 4TB, UK; gwc26@cam.ac.uk (G.W.C.); francesca.ferrara@stjude.org (F.F.)

2 Department of Molecular and Developmental Medicine, University of Siena, 53100 Siena, Italy; trombetta@unisi.it (C.M.T.); emanuele.montomoli@unisi.it or emanuele.montomoli@vismederi.com (E.M.)

3 VisMederi srl, 53100 Siena, Italy

* Correspondence: n.temperton@kent.ac.uk

+ Current address: Laboratory of Viral Zoonotics, University of Cambridge, Cambridge CB2 1TN, UK.

$\ddagger$ Current address: Vector Development \& Production, St. Jude Children's Research Hospital, Memphis, TN 38105, USA.

Citation: Carnell, G.W.; Trombetta, C.M.; Ferrara, F.; Montomoli, E.; Temperton, N.J. Correlation of Influenza B Haemagglutination Inhibiton, Single-Radial Haemolysis and Pseudotype-Based

Microneutralisation Assays for Immunogenicity Testing of Seasonal Vaccines. Vaccines 2021, 9, 100. https://doi.org/10.3390/

vaccines 9020100

Academic Editors: Ewan Plant and Hang Xie

Received: 18 November 2020

Accepted: 21 January 2021

Published: 28 January 2021

Publisher's Note: MDPI stays neutral with regard to jurisdictional claims in published maps and institutional affiliations.

Copyright: (c) 2021 by the authors. Licensee MDPI, Basel, Switzerland. This article is an open access article distributed under the terms and conditions of the Creative Commons Attribution (CC BY) license (https:/ / creativecommons.org/licenses/by/ $4.0 /)$.

\begin{abstract}
Influenza B is responsible for a significant proportion of the global morbidity, mortality and economic loss caused by influenza-related disease. Two antigenically distinct lineages cocirculate worldwide, often resulting in mismatches in vaccine coverage when vaccine predictions fail. There are currently operational issues with gold standard serological assays for influenza B, such as lack of sensitivity and requirement for specific antigen treatment. This study encompasses the gold standard assays with the more recent Pseudotype-based Microneutralisation assay in order to study comparative serological outcomes. Haemagglutination Inhibition, Single Radial Haemolysis and Pseudotype-based Microneutralisation correlated strongly for strains in the Yamagata lineage; however, it correlated with neither gold standard assays for the Victoria lineage.
\end{abstract}

Keywords: influenza B viruses; serology

\section{Introduction}

Influenza is a respiratory syndrome caused by three of six genera in the Orthomyxoviridae family, influenza A, B and C. A fourth genus (Influenza D) has also been characterised [1]. Influenza A virus is the most widespread; its various subtypes are classified according to their antigenically variable surface glycoproteins: haemagglutinin (HA, H1H18) and neuraminidase (NA, N1-N11).

Influenza B viruses comprise two co-circulating, antigenically distinct lineages that diverged from their progenitor, strain B/Hong Kong/8/1973, into the "Yamagata-like" (B/Yamagata/16/1988 type) and "Victoria-like" (B/Victoria/2/1987 type) lineages [2]. This human virus causes a significant proportion (20-30\%) of global morbidity associated with influenza virus disease due to its global distribution and unpredictable switches in the predominating lineage circulating [3-5]. The WHO vaccine recommendations include an up-to-date strain from both lineages for quadrivalent vaccines, but only one for trivalent vaccines. Should the circulating lineage not match the predicted lineage, there is an inevitable drop in coverage against influenza B-linked disease [3,6-8]. In the United States, multiple quadrivalent vaccines have been approved and are in use [9]. 


\subsection{Serological Assays for Influenza B}

Single Radial Immuno-Diffusion (SRID) has been one of the mainstays for the identification and characterisation of inactivated influenza vaccines, correlating with immunogenicity and clinical benefit/protection [10-17]. Haemagglutination Inhibition (HI) has been used for many decades as the tool used for the detection of influenza antibodies [18]. These assays, in combination with ELISA [19] and Single Radial Haemolysis (SRH) [20] comprise the gold standard assays for detection of influenza virus targeting antibodies and are generally applicable to the B type. However, more recent work has highlighted distinct shortcomings of the traditional assays, focusing research on the development of novel assays utilising various different technologies [21-30]. Ether treatment has been employed for influenza B viruses, prior to HI experiments, raising the efficacy of the HI test to that of the Complement Fixation (CF) test [31-33]. This technique was developed due to the lack of reactivity of certain strains of influenza, as well as the B type. Alongside the adaptation of SRID to influenza B resulting in SRH, historical use of ether treatment was found to increase sensitivity but reduces the specificity of HI during assay of serum samples against influenza B [20,31,32,34-37]

\subsection{Monoclonal Antibodies}

Monoclonal antibodies (mAbs) are increasingly being used in influenza research, whether for development of standards to complement or validate assays, or more directly to evaluate Haemagglutinin (HA) epitopes targeted through vaccination, or as potential therapeutics, as seen in the recent Ebola outbreak [38,39]. The mAbs employed in this study were developed as an antibody-based alternative for influenza B identity (Yamagata or Victoria lineages) and potency assays [40].

\subsection{Study Aims}

This study's goal is determining the correlation of the gold standard assays HI and SRH with the recently adapted influenza B Pseudotype-based Microneutralisation assay (pMN), as HI detects primarily receptor binding site (RBS) proximal antibodies while SRH detects IgG1, IgG3 and IgM class antibodies that are compatible with the complement cascade. pMN detects HA-neutralising antibodies directed against both the globular head and the stalk [41]. As with SRH, $\mathrm{HI}$ has been correlated with protection against influenza, with titres at or above 40 linked to $50 \%$ or greater protection from infection in adults [12,42-44]. Linking either of these assays with pMN, despite the detection of different types of antibody, would allow more confidence to be attributed to the results generated using this assay, despite it actually detecting neutralisation of the function of the influenza HA glycoprotein. Correlation data between assays is important for in-depth interpretation of immunogenicity data, especially when correlation is determined with an assay that has been used for in vivo or challenge studies, establishing a correlate of protection. By inter-comparison of assays utilising different approaches, the scientific community can make more informed decisions on the future direction of vaccine design and testing. To date, no study of this type has been performed using influenza B, with efforts focusing more on the predominant A type [45,46]. As a major contributor to morbidity and mortality, it is essential to interrogate the correlations and relationships between data produced for influenza B using a range of assays. This is especially important as this type is lacking a definitive reservoir and circulates yearly as part of two lineages. In this study, influenza B lentiviral pseudotypes (PV) will be interrogated using a defined set of $\mathrm{mAbs}$ and a panel of sera, to put this resource to use in the correlation of $\mathrm{pMN}, \mathrm{SRH}$ and $\mathrm{HI}$.

\section{Materials and Methods}

\subsection{Plasmids}

Expression plasmid phCMV1 bearing the HA gene for B/Hong Kong/8/1973, B/Yamagata/16/1988 and B/Florida/4/2006 were obtained from Dr Davide Corti, Institute for Research in Biomedicine, Bellinzona, Switzerland. B/Victoria/60/2008, 
B/Brisbane/60/2008 and B/Bangladesh/3333/2007 HA genes were subcloned into plasmid pI.18. Plasmids p8.91 and pCSFLW were obtained from Prof. Greg Towers, University College, London, and originate from gene therapy applications $[47,48]$. To achieve maturation of HA gene products, protease-encoding plasmids were used [49-52], as detailed in Table 1 alongside the quantity transfected per well of a 6-well plate. Information regarding the strains of influenza B used can also be found in Table 1.

Table 1. Influenza B strains, accession numbers, lineage, protease type and quantity required for production in 6-well format are displayed. Human Airway Trypsin (HAT) and Transmembrane protease, serine 4 (TMPRSS4) expression plasmids were co-transfected with other plasmids to allow maturation of HA0 to HA1/2 inside producer cells.

\begin{tabular}{ccccc}
\hline Strain & Accession & Lineage & Protease & ng per 6-Well \\
\hline B/Hong Kong/8/1973 & K00425 & Pre-split & HAT & 125 \\
\hline B/Victoria/2/1987 & FJ766840 & Victoria & HAT & 125 \\
\hline B/Brisbane/60/2008 & KX058884 & Victoria & TMPRSS4 & 125 \\
\hline B/Yamagata/16/1988 & CY018765 & Yamagata & HAT & 125 \\
\hline B/Florida/4/2006 & EU515992 & Yamagata & HAT & 125 \\
\hline B/Bangladesh/3333/2007 & CY115255 & Yamagata & HAT & 250 \\
\hline
\end{tabular}

\subsection{Serum Samples}

One serum set was used per lineage of influenza B, consisting of samples taken pre and post seasonal vaccination. Paired low and high responders (based on $\mathrm{HI}$ results) were chosen. In total, 41 pairs of sera were assayed against B/Brisbane/60/2008 and 43 pairs against $B /$ Florida/04/2006. Anonymised serum samples were obtained from Italian subjects and in compliance with Italian ethics law.

\subsection{Pseudotype Production}

Lentiviral pseudotypes were produced by transient transfection of HEK293T/17 cells with lentiviral packaging construct plasmids p8.91 [48] and pCSFLW [47] alongside an influenza B glycoprotein expression plasmid and corresponding protease expression plasmid as described in Section 2.1. Cells were transfected with $500 \mathrm{ng}$ HA expression plasmid and corresponding protease listed in Table 1, alongside $500 \mathrm{ng}$ p8.91 and $750 \mathrm{ng}$ pCSFLW per well in a 6-well format. After $8 \mathrm{~h}$, media was replaced and 1 unit of exogenous neuraminidase (Clostridium perfringens, Sigma, St. Louis, MO, USA) added per well to enable HA-pseudotype release. Cell culture supernatants were harvested $48 \mathrm{~h}$ post-transfection, filtered at $0.45 \mu \mathrm{m}$ and titrated for transduction-based (firefly) luciferase activity on HEK293T /17 cells in 96-well format (Supplementary Figure S1).

\subsection{Pseudotype-Based Microneutralisation Assay}

Serial (1:2) dilutions of serum were performed in 96-well format in a total volume of $50 \mu \mathrm{L}$, and $50 \mu \mathrm{L}$ of lentiviral pseudotype added to give a total relative luminescence (RLU) output of $1 \times 10^{6} \mathrm{RLU}$ per well. Serum and virus were incubated for $1 \mathrm{~h}$ at $37^{\circ} \mathrm{C}$, $5 \% \mathrm{CO}_{2}$ in a humidified incubator, then $1.5 \times 10^{4} \mathrm{HEK} 293 \mathrm{~T} / 17$ cells were added per well. Plates were then incubated at $37^{\circ} \mathrm{C}, 5 \% \mathrm{CO}_{2}$ in a humidified incubator for $48 \mathrm{~h}$, whereupon $50 \mu \mathrm{L}$ of Bright-Glo (Promega) reagent was added per well and luminescence read after a 5 min incubation period. Data points were normalised to $100 \%$ and $0 \%$ neutralisation plate controls, and non-linear regressional analysis was performed to obtain neutralisation curves and $\mathrm{IC}_{50}$ and $\mathrm{IC}_{90}$ values. $\mathrm{R}^{2}$ values of 0.8 or more were used as a cut-off for confidence in the titration of antibody response, and any samples below this were discarded. 


\subsection{Haemagglutination Inhibition Assay}

The influenza viruses used in the HI were B/Brisbane/06/2008 (15/146) and B/Florida/04/2006 (08/138), obtained from the National Institute for Biological Standards and Control (NIBSC), United Kingdom. Serum samples were pre-treated with receptor destroying enzyme (RDE) from Vibrio cholerae (Sigma Aldrich) at 1:5 ratio for $18 \mathrm{~h}$ at $37^{\circ} \mathrm{C}$ in a water bath and then heat-inactivated for $1 \mathrm{~h}$ at $56^{\circ} \mathrm{C}$ in a water bath with $8 \%$ sodium citrate at a 1:4 ratio. Turkey erythrocytes (Emozoo S.N.C, Casole d'Elsa, Italy) were centrifuged twice, washed with a saline solution $(0.9 \%)$ and adjusted to a final dilution of $0.35 \%$. RDE-treated serum samples were diluted two-fold with saline solution $(0.9 \%)$ in a 96 -well plate, starting from an initial dilution of 1:10. $25 \mu \mathrm{L}$ of influenza virus was added to each well, and the mixture was incubated at room temperature for $1 \mathrm{~h}$. At the end of the incubation, erythrocytes were added and the plates were evaluated for the inhibition of agglutination after $1 \mathrm{~h}$ at room temperature.

The antibody titre was expressed as the reciprocal of the highest serum dilution showing complete inhibition of agglutination. Since the starting dilution was 1:10, the lower limit of detectable antibody titre was 10 . When the titre was below the detectable threshold, the results were conventionally expressed as 5 for calculation purposes, half the lowest detection threshold. Geometric mean titers were calculated from experimental repeats.

\subsection{Single Radial Haemolysis Assay}

The influenza viruses B/Brisbane/06/2008 (15/146) and B/Florida/04/2006 (08/138) were obtained from the NIBSC. Serum samples were heat-inactivated at $56{ }^{\circ} \mathrm{C}$ for $30 \mathrm{~min}$ in a water bath. Turkey erythrocytes were centrifuged twice and washed with phosphatebuffered saline (PBS). Diluted virus was added to the erythrocyte suspension at a concentration of 2000 haemagglutination units (HAU) per mL. The erythrocyte-virus suspension was incubated at $4{ }^{\circ} \mathrm{C}$ for $20 \mathrm{~min}$, and subsequently, a solution of $2.5 \mathrm{mM}$ Chromium Chloride $\left(\mathrm{CrCl}_{3}\right)$ was added to the suspension, and it was incubated at room temperature for $10 \mathrm{~min}$. The suspension was then carefully mixed once and then centrifuged. A stock solution consisting of $1.5 \%$ agarose in PBS containing $0.1 \%$ sodium azide and $0.5 \%$ low gelling agarose was prepared. This agarose stock solution was maintained at $45^{\circ} \mathrm{C}$ in a water bath. The final suspension of erythrocytes, virus and guinea pig complement was vigorously shaken and evenly spread onto each plate. Plates were incubated at room temperature for $30 \mathrm{~min}$ and then stored at $4{ }^{\circ} \mathrm{C}$ for $30-90 \mathrm{~min}$. Holes were introduced into each plate with a calibrated punch, and $6 \mu \mathrm{L}$ of each serum sample was dispensed into each hole. The plates were stored in a humid box and incubated at $4{ }^{\circ} \mathrm{C}$ for $16-18 \mathrm{~h}$ in the dark. Subsequently, plates were incubated in a water bath at $37^{\circ} \mathrm{C}$ for $90 \mathrm{~min}$; diameters of the areas of haemolysis were then read in $\mathrm{mm}$ with a calibrating viewer $[20,53]$.

\section{7. $m A$ s s and Controls}

Influenza B mAbs were kindly provided by Dr Jerry P Weir, Division of Viral Products, Food and Drug Administration (FDA), USA [40]; see Table 2. Anti-B/Brisbane/60/2008 HA serum (11/136) was obtained from the NIBSC and employed against all strains of influenza $B$ as a serum positive control. This antiserum had previously been tested in our laboratory, showing that it was capable of neutralising all available strains of influenza $B$ to varying degrees, with the highest potency against the matched B/Brisbane/60/2008 strain [54].

Table 2. Influenza B mAbs. Five mAbs used, two specific for each lineage of influenza $B$ and one binding to an epitope conserved between both lineages (cross).

\begin{tabular}{cccccc}
\hline $\mathrm{mAb}$ & $\mathbf{2 F 1 1}$ & 3E8 & $\mathbf{1 H 4}$ & $\mathbf{8 E 1 2}$ & 5A1 \\
\hline Target lineage & Cross & Yamagata & Yamagata & Victoria & Victoria \\
\hline
\end{tabular}




\subsection{Statistical Analysis}

Mean endpoint antibody titres (or $\mathrm{IC}_{50}$ for $\mathrm{pMN}$ ) for each serum sample were compared between assays. This comparison was carried out in GraphPad Prism where a two-tailed Pearson's correlation was performed on pairs of data sets that were plotted against each other. A line of best fit was used in order to show the general trend of correlation between data sets. Analysis was performed between pre- (V1) and post-vaccination (V2) sera, and fold change from V1 to V2. pMN data consisted of both $\mathrm{IC}_{50}$ and $\mathrm{IC}_{90}$ values, and further analysis was carried out on transformed (log10) V2 data.

\section{Results}

\subsection{Lineage Specific and Cross-Reacting $m A$ As Neutralise Influenza B PV}

Lineage-specific mAbs neutralised all influenza B PV except B/Brisbane/60/2008, which was not susceptible in our experiments. This PV was unaffected by either the Victoria specific mAbs, or the $2 \mathrm{~F} 11$ cross-lineage $\mathrm{mAb}$. Despite this, anti-B/Brisbane/60/2008 HA serum showed the highest neutralisation against the matched $B /$ Brisbane/60/2008 pseudotypes $\left(\mathrm{IC}_{50}>256,000\right)$ (Figure 1). The $2 \mathrm{~F} 11 \mathrm{mAb}$ neutralised Yamagata lineage strains the strongest ( $\mathrm{IC}_{50}: 2-4 \mathrm{ng} / \mathrm{mL}$ ), followed by the pre-lineage strain B/Hong Kong/8/1973 $\left(\mathrm{IC}_{50}: 8 \mathrm{ng} / \mathrm{mL}\right)$ and finally the Victoria strain B/Victoria/2/1987 $\left(\mathrm{IC}_{50}: 160 \mathrm{ng} / \mathrm{mL}\right)$. Yamagata lineage-specific mAbs 3E8 and 1H4 were only effective on Yamagata lineage PVs, neutralising $\mathrm{B} /$ Bangladesh/3333/2007, the strongest $\left(\mathrm{IC}_{50}: 3\right.$ and $4 \mathrm{ng} / \mathrm{mL}$, respectively), followed by B/Florida/4/2006 ( $\mathrm{IC}_{50}$ : 21 and $3 \mathrm{ng} / \mathrm{mL}$ ) and B/Yamagata $\left(\mathrm{IC}_{50}\right.$ : 34 and $6 \mathrm{ng} / \mathrm{mL}$ ). Victoria-specific $\mathrm{mAbs} 8 \mathrm{E} 12$ and $5 \mathrm{~A} 1$ neutralised B/Hong Kong the strongest $\left(\mathrm{IC}_{50}: 2\right.$ and $4 \mathrm{ng} / \mathrm{mL}$, respectively), followed by B/Victoria/2/1987 (IC $\mathrm{I}_{50}: 47$ and 22). See Table 3 for a list of $\mathrm{IC}_{50}$ values.

\section{B/Brisbane/60/2008 Antisera \\ vs. influenza B PV}

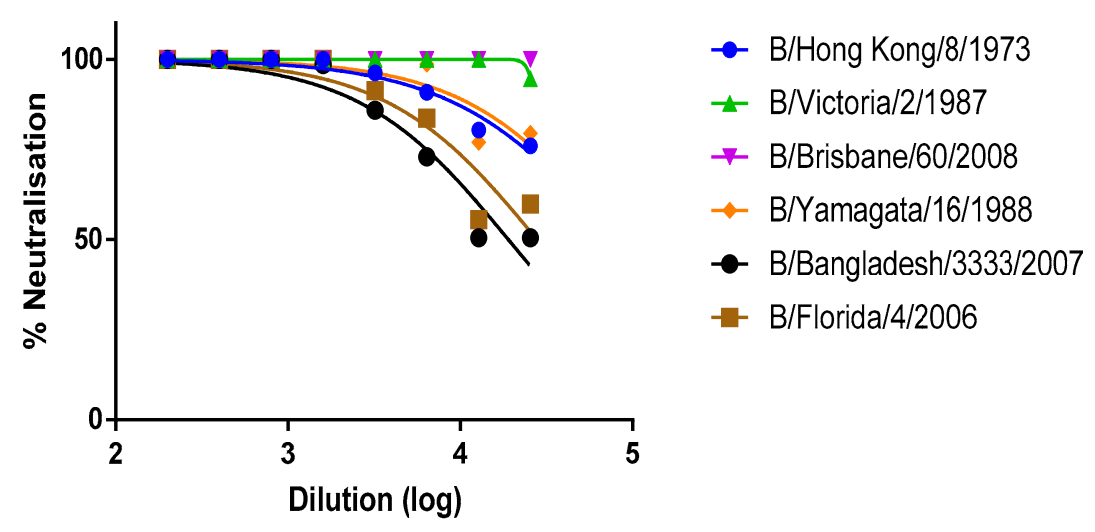

Figure 1. Anti-B/Brisbane/60/2008 HA serum (11/136, NIBSC) neutralises matched and related strains B/Brisbane/60/2008 and B/Victoria/2/1987 the strongest but also neutralises Yamagata lineage strains and the B/Hong Kong/7/1973 precursor to a lesser extent. 
Table 3. $\mathrm{IC}_{50}$ values in $\mathrm{ng} / \mathrm{mL}$ for the neutralisation of 6 strains of influenza B HA-PV by mAbs. Pre-lineage strain, Yamagata and Victoria lineages highlighted in grey, green and blue, respectively. With the exception of B/Brisbane/60/2008, the cross lineage mAb 2F11 acts as expected, neutralising all influenza B PV. Yamagata specific mAbs neutralise PV bearing HAs from Yamagata lineage strains, while Victoria-specific mAbs neutralise PV bearing HAs from Victoria lineage strains with the exception of B/Brisbane/60/2008. The pre-lineage spli t strain B/Hong Kong/8/1973 is neutralised in a Victoria-like manner by 2F11 and Victoria lineage-specific mAbs 8E12 and 5A1.

\begin{tabular}{|c|c|c|c|c|c|c|c|}
\hline mAb & Target & $\begin{array}{c}\text { B/Hong } \\
\text { Kong/8/1973 }\end{array}$ & B/Florida/4/2006 & B/Bangladesh/3333/2007 & B/Victoria/2/1987 & B/Brisbane/60/2008 \\
\hline $2 \mathrm{~F} 11$ & Cross & 8 & 3 & 21 & 4 \\
\hline $3 \mathrm{E} 8$ & Yamagata & - & 34 & 3 & - \\
\hline $1 \mathrm{H} 4$ & Yamagata & - & 6 & - & - \\
\hline $8 \mathrm{E} 12$ & Victoria & 2 & - & - \\
\hline $5 \mathrm{~A} 1$ & VIctoria & 4 & - & - \\
\hline
\end{tabular}

Anti B/Brisbane/60/2008 polyclonal sheep serum was used as an anti-influenza B control in all of these experiments and for all strains of influenza B PV due to its ability to neutralise all strains tested in the pMN assay, regardless of lineage. This antiserum is most potent against the homologous strain B/Brisbane/60/2008 and the other Victoria lineage strain B/Victoria/2/1987 (Figure 4), and 100\% neutralisation is seen from 1:200 up to the penultimate dilution point 1:128,000.

The data for the Victoria lineage viruses show reduced antibody potency, with $\mathrm{IC}_{50}$ values up to 20 times higher. Victoria epitope targeting mAbs neutralise B/Victoria as well as the Hong Kong precursor. Neutralisation curves for the above data are shown in Figures 2-4.

\section{B/Hong Kong/8/1973 (pre split)}

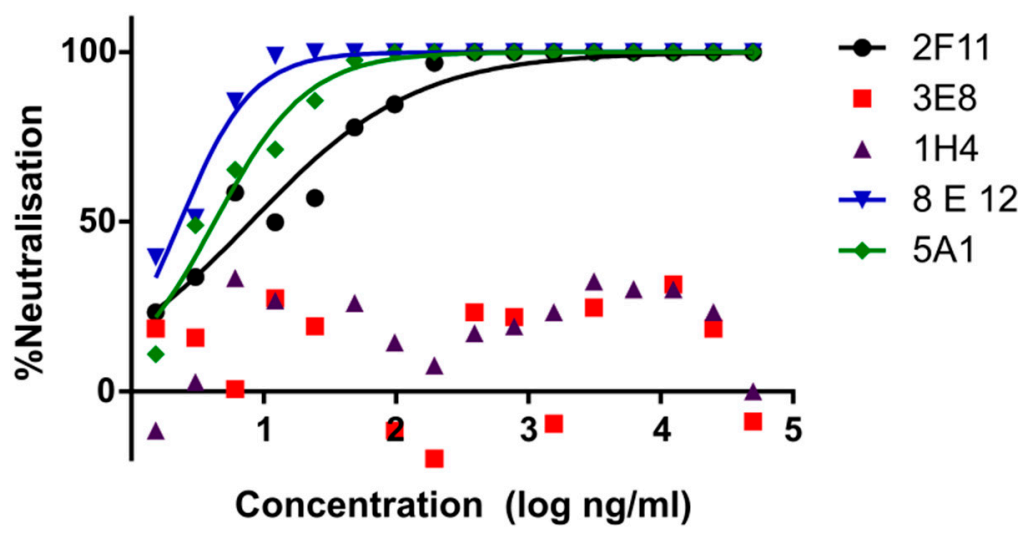

Figure 2. pMN neutralisation curves for FDA mAbs 2F11, 3E8, 1H4, 8E12 and 5A1 against PV bearing the HA glycoprotein from the influenza B pre-lineage split strain, B/Hong Kong/8/1973. This PV is neutralised strongly by Victoria-specific mAbs 5A1, 8E12 and cross-lineage mAb 2F11 but not Yamagata specific mAbs 3E8 or $1 \mathrm{H} 4$. 
B/Victoria/2/1987

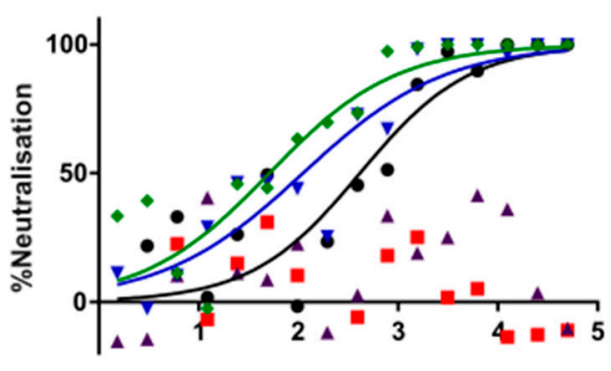

B/Brisbane/60/2008

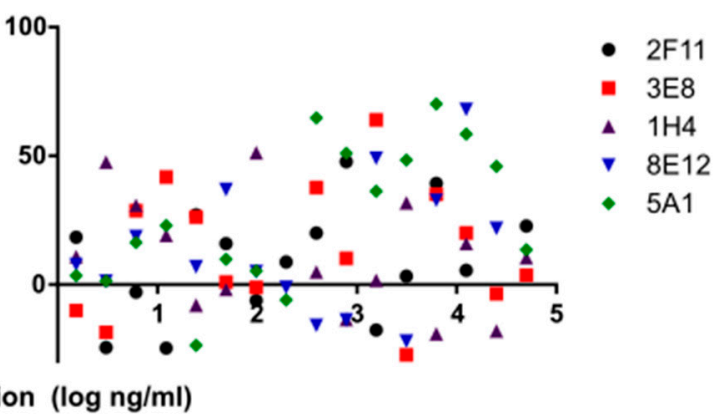

Figure 3. pMN neutralisation curves for FDA mAbs 2F11, 3E8, 1H4, 8E12 and 5A1 against PV bearing HA glycoproteins from Victoria lineage strains B/Victoria/2/1987 and B/Brisbane/60/2008. Victoria lineage PVs are not neutralised by Yamagata-specific mAbs 3E8 or 1H4. A/Victoria/2/1987 PV is neutralised by Victoria lineage-specific mAbs 5A1, 8E12 and cross-lineage mAb 2F11. B/Brisbane/60/2008 PV are not neutralised by any of the mAbs tested, including Victoria lineage and cross-lineage $\mathrm{mAbs}$ with a high degree of assay variability.

B/Bangladesh/3333/2007

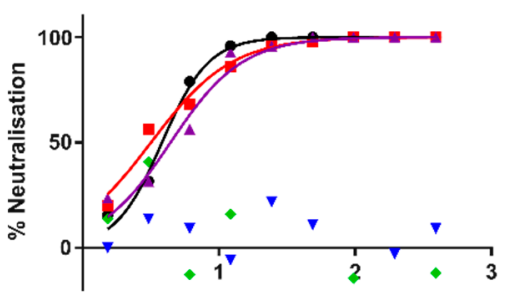

B/Florida/4/2006

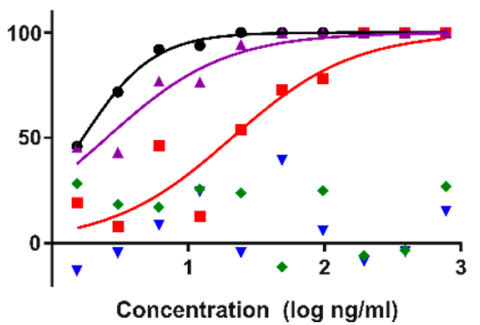

B/Yamagata/16/1988

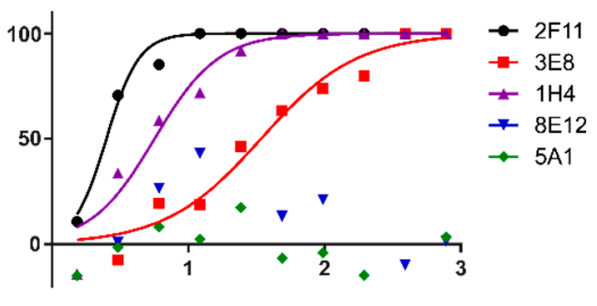

Figure 4. pMN neutralisation curves for FDA mAbs 2F11, 3E8, 1H4, 8E12 and 5A1 against PV bearing HA glycoproteins from Yamagata lineage strains B/Yamagata/16/1988, B/Florida/4/2006 and B/Bangladesh/3333/2007. Potent neutralisation by Yamagata specific mAbs 3E8 and 1H4, and by cross-lineage mAb 2F11. No neutralisation is observed for Victoria lineage-specific mAbs 8E12 and 5A1.

\subsection{Correlation of $S R H, H I$ and $p M N$}

SRH, HI and pMN data for strains B/Florida/04/2006 (Yamagata) and B/Brisbane/60/2008 (Victoria) were analysed to assess the correlation between each assay. Endpoint titres for high responders (V2) are displayed in Figure 5. The titre profiles of each serum set are very similar between the two viruses, despite each virus having its own unique set of sera. HI values range from 5 to 1280 for both B/Brisbane/60/2008 and B/Florida/04/2006, with arithmetic means at 156 and 270, respectively. SRH values range from 37 to 106 and 38 to $99 \mathrm{~mm}^{2}$ for B/Brisbane/60/2008 and B/Florida/04/2006, respectively. Arithmetic means were 58 and $57 \mathrm{~mm}^{2}$, respectively. pMN ( $\mathrm{IC}_{50}$ ) values ranged from 4594 to 209,395 for B/Brisbane/60/2008 and 3349 to 31,954 for B/Florida/04/2006. Arithmetic mean pMN titre means were 41,613 and 11,740 , respectively. 
B/Brisbane/60/2008

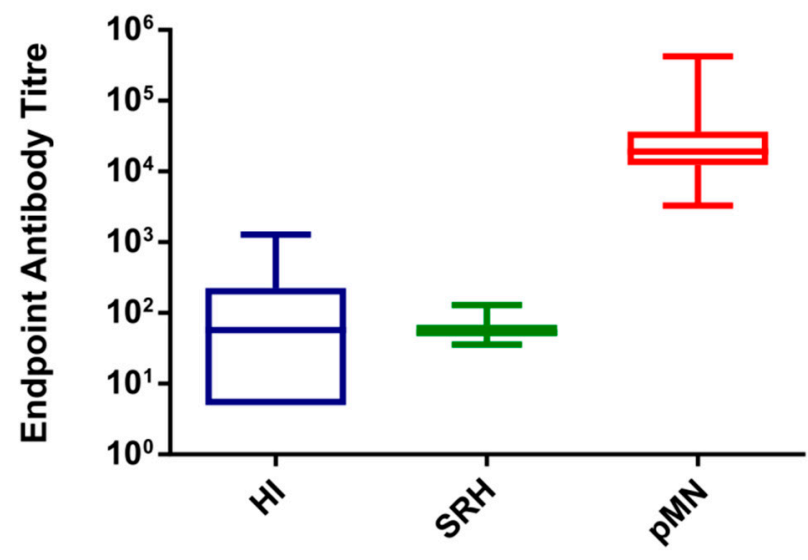

B/Florida/04/2006

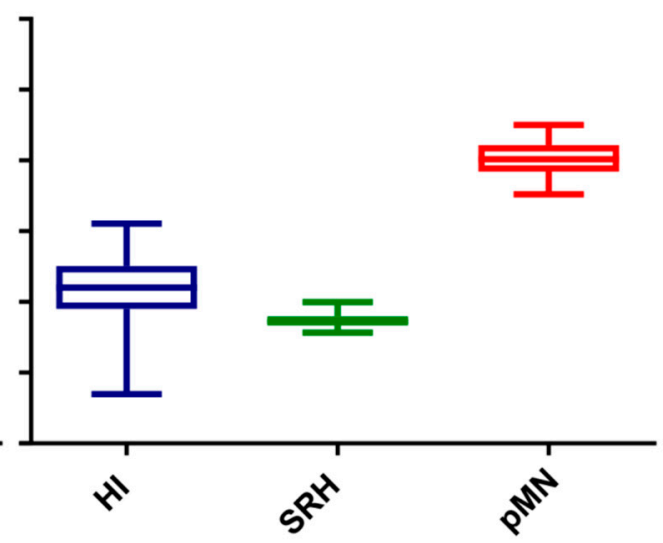

Figure 5. Haemagglutination Inhibition (HI), Single Radial Haemolysis (SRH) endpoint titres and pMN IC $\mathrm{I}_{50}$ values for high responders (V2) against B/Brisbane/60/2008 and B/Florida/04/2006. Titres displayed show similar profiles for each strain tested, with a broader range of $\mathrm{pMN} \mathrm{IC}_{50}$ values for B/Brisbane/60/2008.

\subsection{Correlation of Data: B/Brisbane/60/2008 IC 50}

Two different sets of values for each assay were correlated, V2 data (post-vaccination high responders) and fold change between V1 and V2. For B/Brisbane/60/2008, no correlation was observed between $\mathrm{pMN}$ and the other assays, with Pearson's $r$ values ranging from -0.07 to -0.08 ( $p=0.13$ to 0.9$)$. SRH and HI correlated when fold changes were compared $(\mathrm{r}=0.224, p=0.1539)$ and increased after the removal of two outliers $(\mathrm{r}=0.60, p \geq 0.0001)$. V1 results weakly correlated $(\mathrm{r}=0.32, p=0.0375)$ for SRH and HI, and more so for V2 results $(r=0.39, p=0.0123)$. See Figures 6 and 7 for correlation graphs and data.

\section{B/Brisbane: V2 (IC50)}

V2: pMN vs SRH

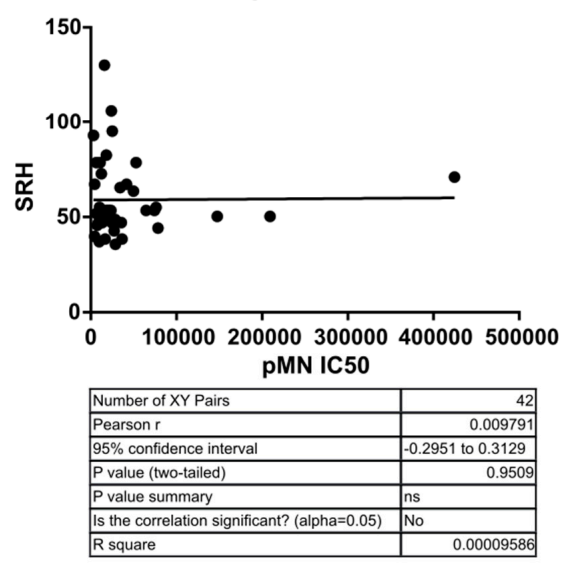

\section{V2: pMN vs HI}
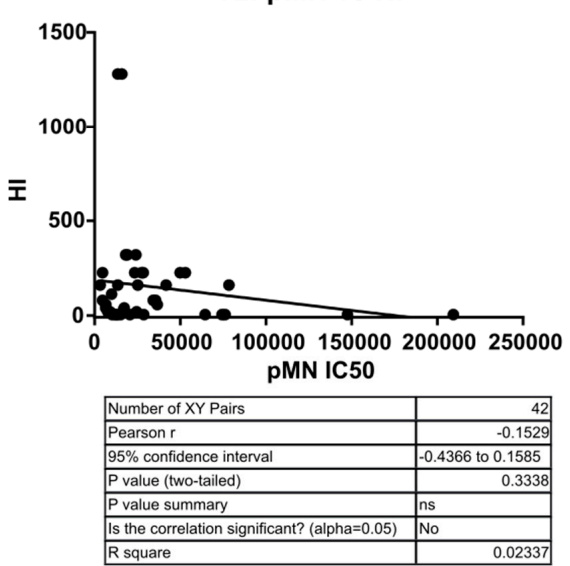

V2: SRH vs HI
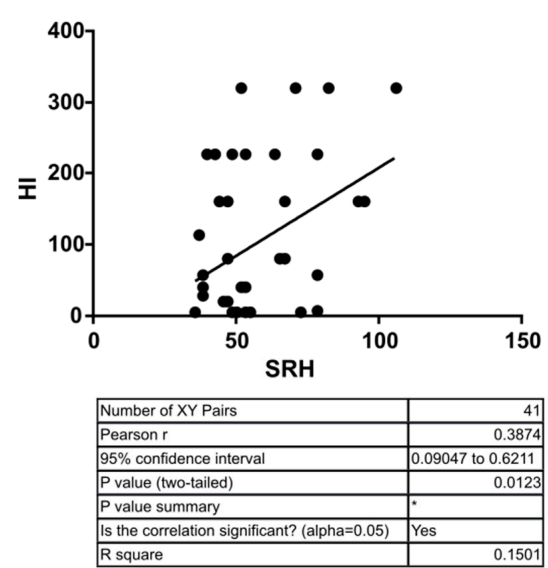

Figure 6. Correlation of SRH, HI and pMN ( $\left.\mathrm{IC}_{50}\right)$ mean V2 values assayed against B/Brisbane/60/2008 PV. Pearson's two-tailed analysis performed using GraphPad Prism. No correlation was observed between $\mathrm{IC}_{50}$ antibody titres and SRH or HI (Pearsons $\mathrm{r}=0.009$ and -0.152 , respectively). SRH and HI values were correlated (Pearsons $\mathrm{r}=0.38$ ). $p>0.05=\mathrm{ns}, p \leq 0.05={ }^{*}$. 


\section{B/Brisbane: V1/V2 Fold change (IC50)}

Fold change: $\mathrm{pMN}$ vs $\mathrm{H}$

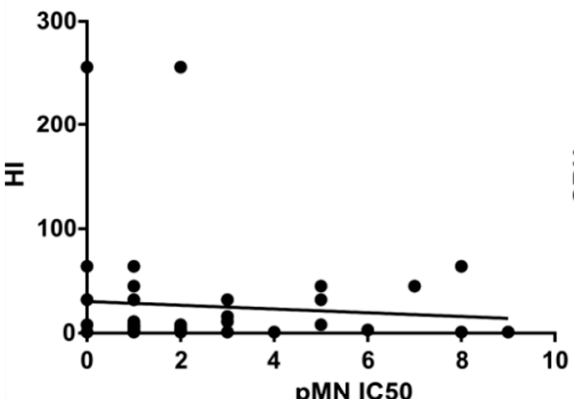

PMN IC50

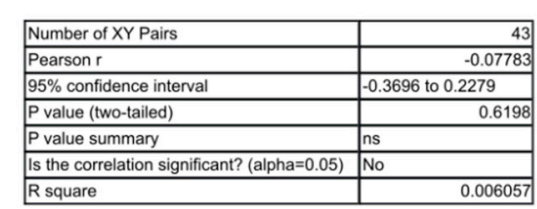

Fold change: $p M N$ vs SRH

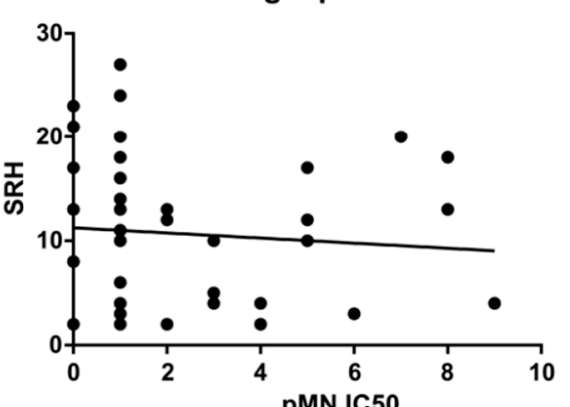

PMN IC50

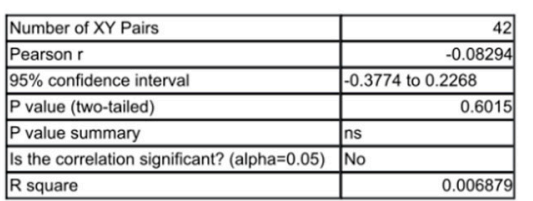

Fold change: SRH vs HI

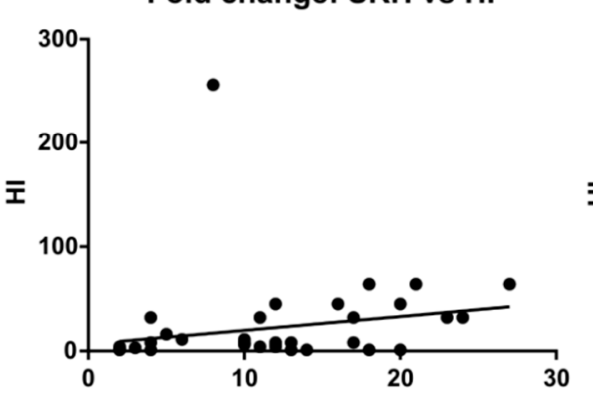

SRH

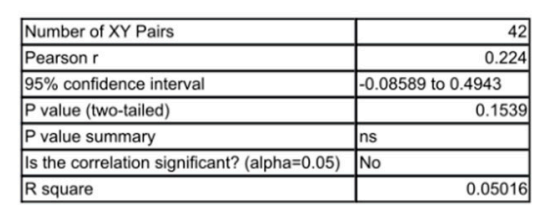

Fold change: SRH vs HI (256 outlier removed)

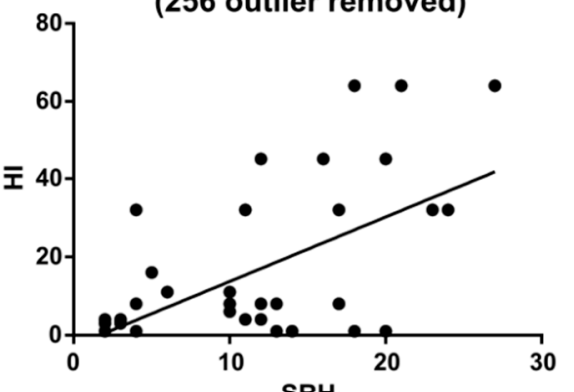

SRH

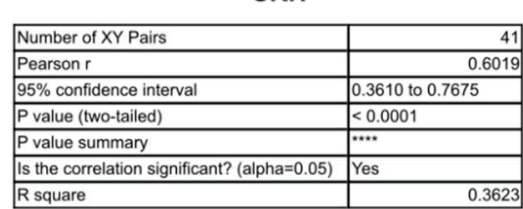

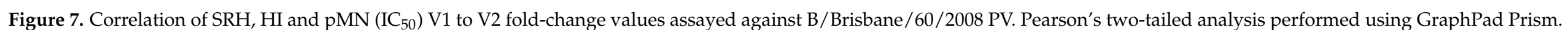

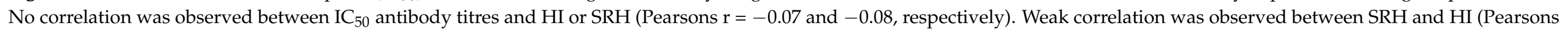
$\mathrm{r}=0.22$ ), which was improved after removal of outlying HI value (Pearsons $\mathrm{r}=0.60$ ). $p>0.05=\mathrm{ns}, p \leq 0.0001={ }^{* * * *}$. 


\subsection{Correlation of Data: B/Brisbane $I_{90}$ and Transformed Data}

Upon transformation of the V2 data to a $\log 10$ scale, correlation was still not observed between $\mathrm{pMN}$ and SRH or HI despite normalization of scales, with a weak correlation between the latter two $(\mathrm{r}=0.35, p=0.0189)$. $\mathrm{pMN} \mathrm{IC}_{90}$ data correlated weakly with $\mathrm{HI}$ and SRH ( $\mathrm{r}=0.37$ and $0.45, p=0.00188$ and 0.0026 , respectively). The correlation seen was reduced by a transformation of $\mathrm{IC}_{90}$ data and comparison on a log scale $(\mathrm{r}=0.23$ and 0.32 , $p=0.132$ and 0.0372 , respectively) (see Figures 8-10).

\section{Brisbane: log10 V2 (IC50)}

V2: $\log \mathrm{SRH}$ vs $\log \mathrm{HI}$

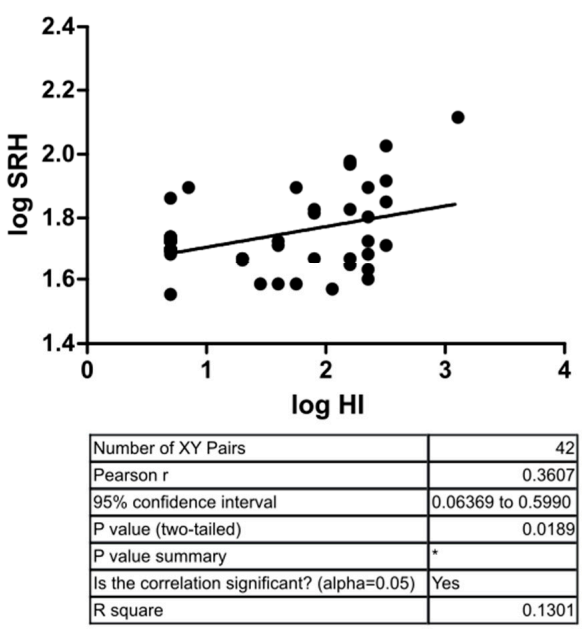

V2: $\log \mathrm{pMN}$ vs $\log \mathrm{HI}$

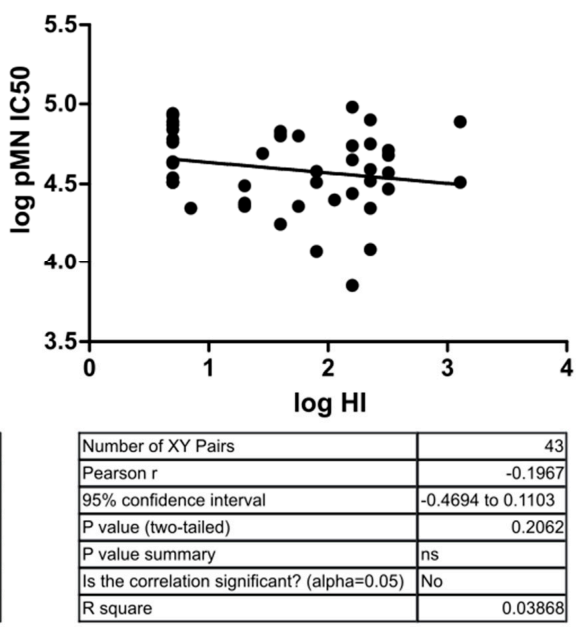

V2: $\log \mathrm{pMN}$ vs $\log$ SRH

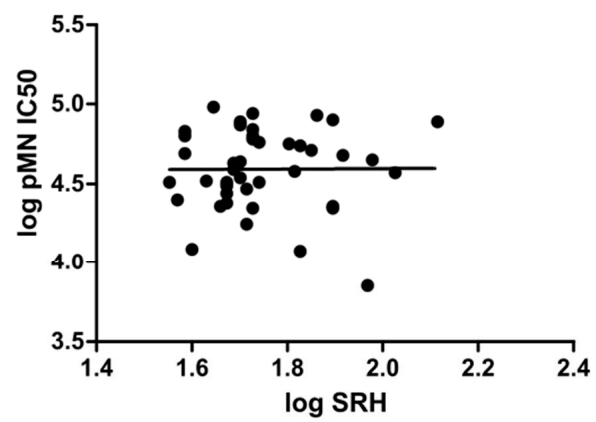

\begin{tabular}{|l|r|}
\hline Number of $X Y$ Pairs & 42 \\
\hline Pearson r & 0.007283 \\
\hline 95\% confidence interval & -0.2974 to 0.3106 \\
\hline P value (two-tailed) & 0.9635 \\
\hline P value summary & ns \\
\hline Is the correlation significant? (alpha $=0.05)$ & No \\
\hline$R$ square & \multicolumn{2}{|c|}{0.00005305} \\
\hline
\end{tabular}

Figure 8. Correlation of transformed $(\log 10) \mathrm{SRH}, \mathrm{HI}$ and $\mathrm{pMN}\left(\mathrm{IC}_{50}\right)$ mean V2 values assayed against $\mathrm{B} / \mathrm{Brisbane} / 60 / 2008$ PV. Pearson's two-tailed analysis performed using GraphPad Prism. Weak correlation was observed between log SRH and $\mathrm{HI}$ values (Pearsons $\mathrm{r}=0.36$ ). No correlation was observed between $\log \mathrm{IC}_{50}$ antibody titres and $\log \mathrm{HI}$ or SRH values (Pearsons $r=-0.196$ and 0.007 , respectively). $p>0.05=\mathrm{ns}, p \leq 0.05=^{*}$.

\section{Brisbane: log10 V2 (IC90)}

V2: $\log$ pMN vs $\log \mathrm{HI}$

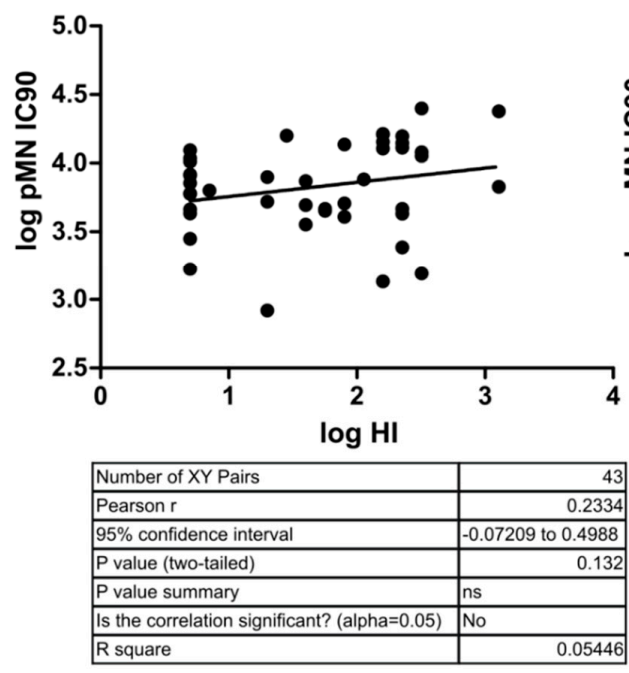

V2: $\log$ pMN vs log SRH

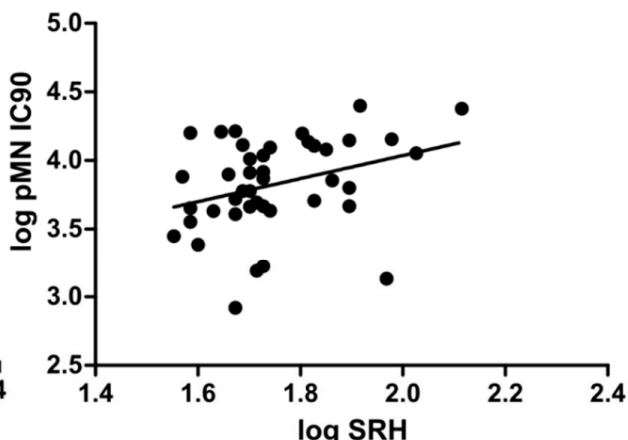

\begin{tabular}{|c|c|}
\hline Number of XY Pairs & 42 \\
\hline Pearson $r$ & 0.3226 \\
\hline $95 \%$ confidence interval & 0.02058 to 0.5706 \\
\hline$P$ value (two-tailed) & 0.0372 \\
\hline$P$ value summary & * \\
\hline Is the correlation significant? (alpha $=0.05$ ) & Yes \\
\hline R square & 0.104 \\
\hline
\end{tabular}

Figure 9. Correlation of transformed $(\log 10)$ data for $\mathrm{pMN}\left(\mathrm{IC}_{90}\right)$ with $\mathrm{HI}$ and $\mathrm{SRH}$ using mean V2 values for sera assayed against B/Brisbane/60/2008 PV. Pearson's two-tailed analysis performed using GraphPad Prism. Weak correlation was observed between $\log \mathrm{IC}_{90}$ antibody titres and $\log \mathrm{HI}$ or SRH values (Pearsons $\mathrm{r}=0.23$ and 0.32 , respectively). $p>0.05=\mathrm{ns}$, $p \leq 0.05{ }^{*}$. 


\section{Brisbane: V2 (IC90)}

\section{V2: pMN vs HI}
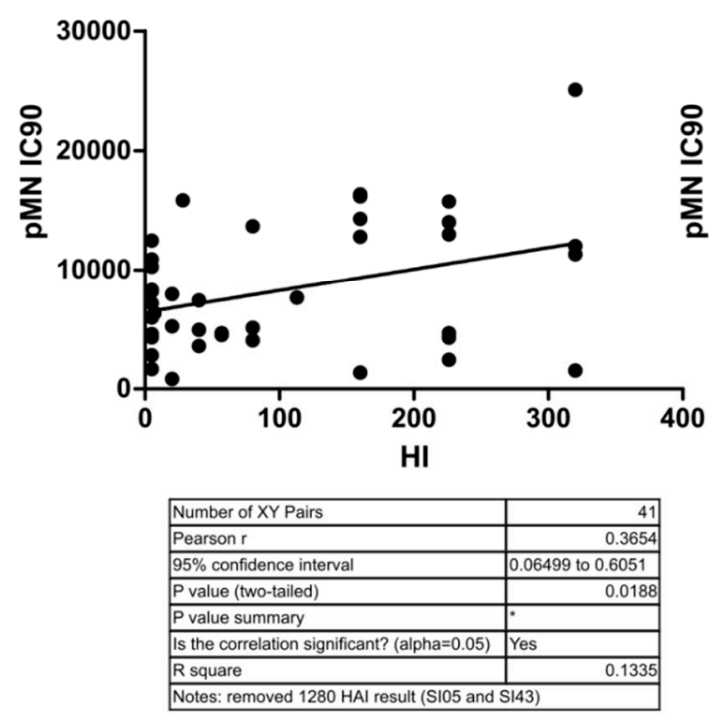

V2: pMN vs SRH

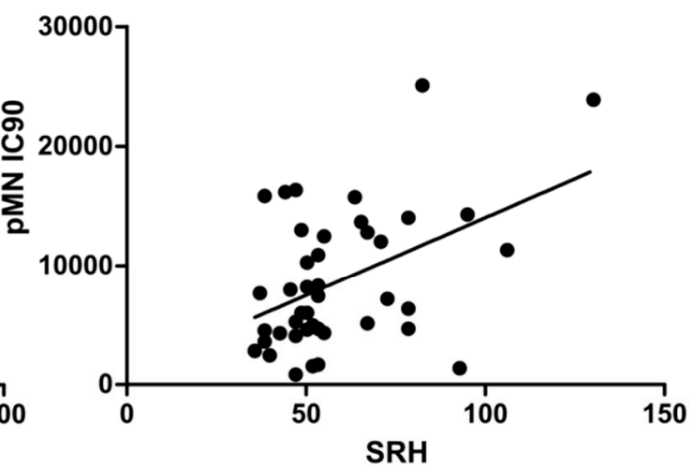

\begin{tabular}{|c|c|}
\hline Number of XY Pairs & 42 \\
\hline Pearson r & 0.4535 \\
\hline $95 \%$ confidence interval & 0.1735 to 0.6657 \\
\hline$P$ value (two-tailed) & $\begin{array}{r}0.0026 \\
\end{array}$ \\
\hline$P$ value summary & 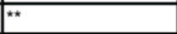 \\
\hline Is the correlation significant? (alpha $=0.05)$ & Yes \\
\hline R square & 0.2057 \\
\hline
\end{tabular}

Figure 10. Correlation of pMN ( $\mathrm{IC}_{90}$ ) with HI and SRH using mean V2 values for sera assayed against B/Brisbane/60/2008 PV. Pearson's two-tailed analysis performed using prism Graph Pad. Weak correlation was observed between IC $\mathrm{C}_{90}$ antibody titres and HI (Pearsons $r=0.36$ ). $\mathrm{IC}_{90}$ values correlated well with SRH values (Pearsons $\mathrm{r}=0.45$ ). $p \leq 0.05={ }^{*}, p \leq 0.01={ }^{* *}$.

\subsection{Correlation of Data: B/Florida/4/2006 IC 50}

In contrast to the results for $\mathrm{B} /$ Brisbane/60/2008, pMN data correlated well with SRH and HI, and V2 SRH and HI correlated strongly $(r=0.79, p \leq 0.0001)$ (see Figure 11). For the fold change data, $\mathrm{pMN}$ correlated with $\mathrm{HI}$ and $\mathrm{SRH}(\mathrm{r}=0.66$ and $0.56, p \leq 0.0001)$. $\mathrm{SRH}$ and HI correlated strongly $(\mathrm{r}=0.72, p \leq 0.0001)$ (see Figure 12). For V2 data, $\mathrm{pMN}$ correlated with SRH $(r=0.46, p=0.0023)$ and $\mathrm{HI}(\mathrm{r}=0.61, p \geq 0.0001)$.

\section{B/Florida: V2 (IC50)}

V2: pMN vs SRH
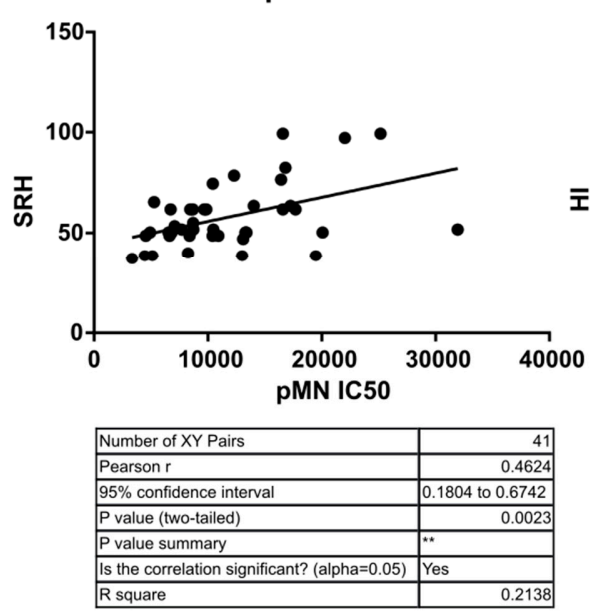

V2: $p M N$ vs HI
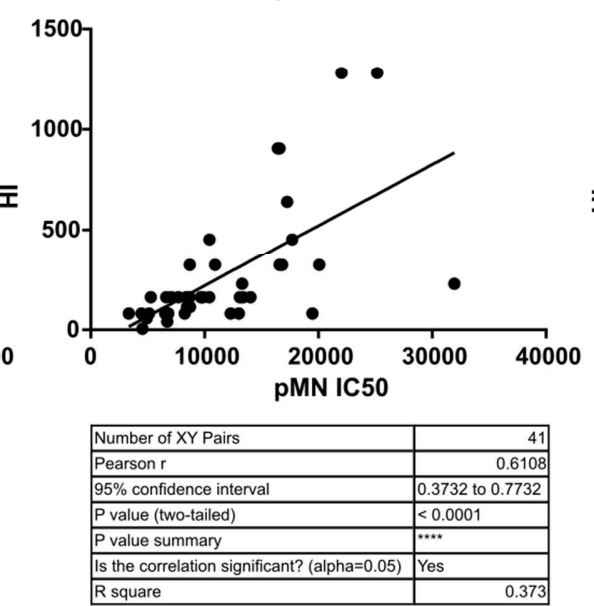

V2: SRH vs HI
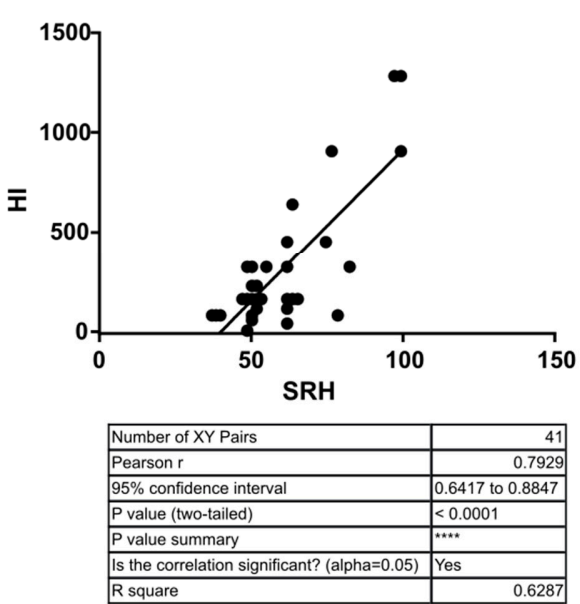

Figure 11. Correlation of SRH, HI and pMN ( $\left.\mathrm{IC}_{50}\right)$ mean V2 values assayed against B/Florida/4/2006 PV. Pearson's two-tailed analysis performed using GraphPad Prism. Weak correlation was observed between $\mathrm{IC}_{50}$ antibody titres and SRH (Pearsons $r=0.46$ ). Strong correlation was observed between $\mathrm{IC}_{50}$ antibody titres and HI (Pearsons $\mathrm{r}=0.61$ ), as well as between SRH and HI (Pearsons $r=0.79$ ) for the V2 data tested. $p \leq 0.01=* *, p \leq 0.0001=* * *$. 


\section{B/Florida: V1/V2 Fold change (IC50)}

\section{Fold change: $\mathrm{pMN}$ vs $\mathrm{HI}$}
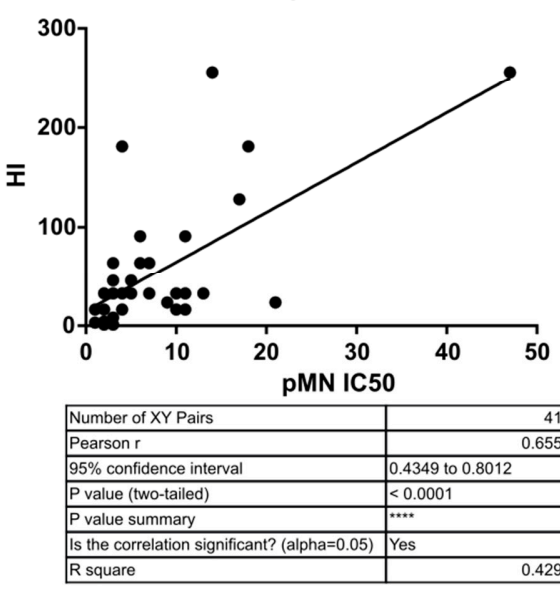

Fold change: $\mathrm{pMN}$ vs SRH
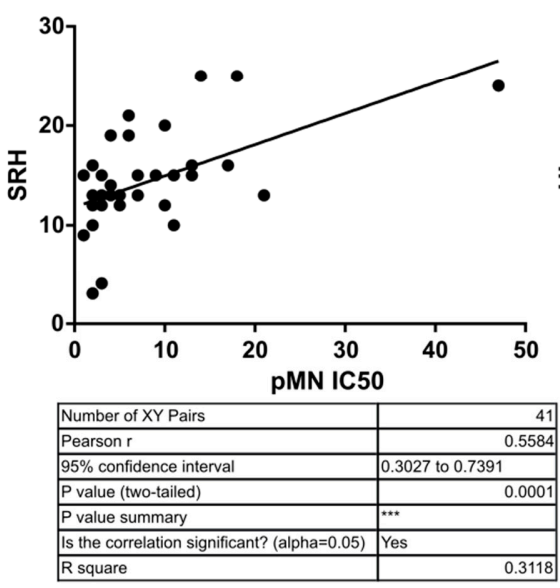

Fold change: SRH vs HI

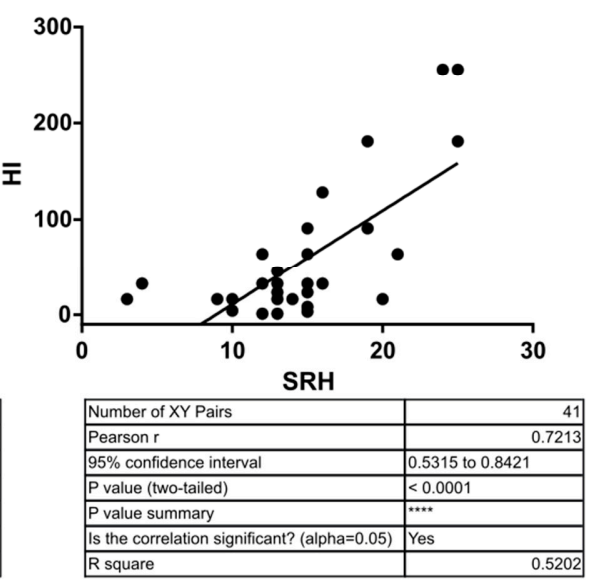

Figure 12. Correlation of SRH, HI and $\mathrm{pMN}\left(\mathrm{IC}_{50}\right) \mathrm{V} 1$ to $\mathrm{V} 2$ fold change values assayed against B/Florida/4/2006 PV. Pearson's two-tailed analysis performed using GraphPad Prism. Strong correlation was seen between fold change in pMN and $\mathrm{HI}$ values between V1 and V2 antibody titres $\left(\mathrm{IC}_{50}\right)$, Pearsons $\mathrm{r}=0.65$. pMN and SRH V1/V2 fold changes correlated well, Pearsons $r=0.55$ and strong correlation was observed for V1/V2 fold change for antibody titres of SRH and HI (Pearsons $\mathrm{r}=0.72) . p \leq 0.001=^{* * *}, p \leq 0.0001=^{* * * *}$.

\subsection{Correlation of Data: B/Florida/4/2006 IC 90 and Transformed Data}

Transformation to a $\log 10$ scale caused a slight reduction in the significance attributed to the correlation between pMN and SRH or HI ( $r=0.57$ or $0.30, p=0.0002$ or 0.0555$)$, but correlation remained strong between all three assays. $\mathrm{IC}_{90}$ data correlated very well between pMN and SRH or HI ( $r=0.85$ and $0.65, p \leq 0.0001)$ and this was maintained when data were transformed to the $\log 10$ scale $(r=0.78$ and $0.62, p \leq 0.0001)$ (see Figures 13-15).

\section{Florida: log10 V2 (IC50)}

V2: $\log$ SRH vs log HI
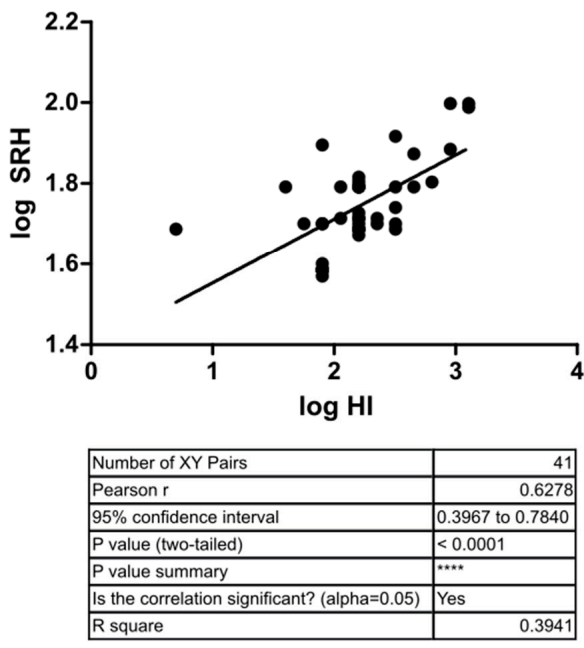

V2: $\log \mathrm{pMN}$ vs $\log \mathrm{HI}$
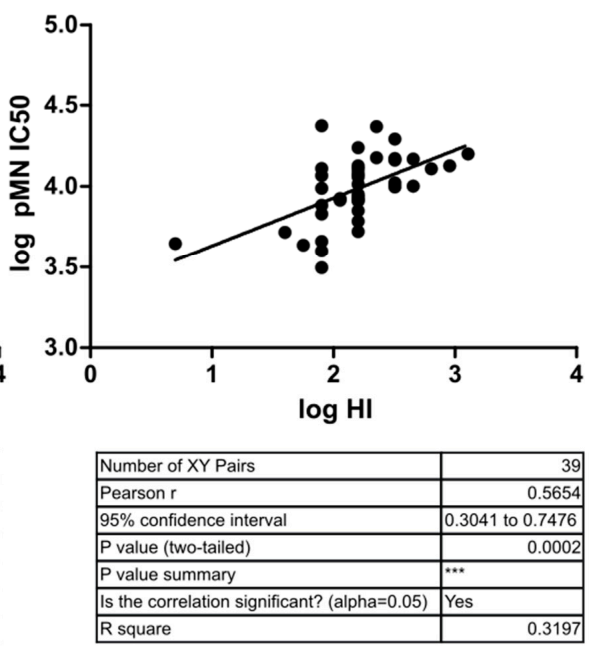

V2: $\log p M N$ vs $\log S R H$

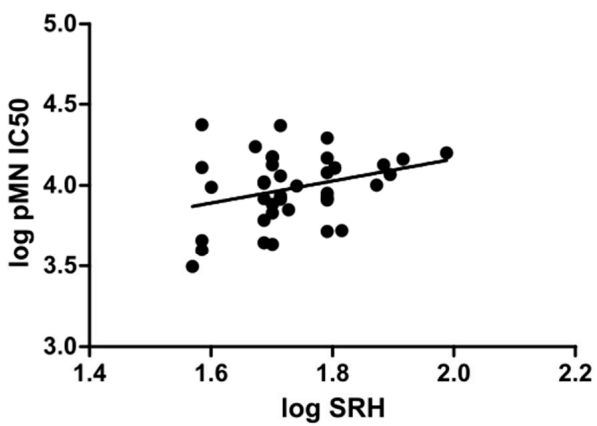

\begin{tabular}{|l|r|}
\hline Number of $X Y$ Pairs & 39 \\
\hline Pearson $r$ & 0.3091 \\
\hline $95 \%$ confidence interval & -0.007192 to 0.56 \\
\hline P value (two-tailed) & 0.0555 \\
\hline P value summary & ns \\
\hline Is the correlation significant? (alpha $=0.05)$ & No \\
\hline R square & \\
\hline
\end{tabular}

Figure 13. Correlation of transformed ( $\log 10) \mathrm{SRH}, \mathrm{HI}$ and $\mathrm{pMN}\left(\mathrm{IC}_{50}\right)$ mean V2 values assayed against $\mathrm{B} /$ Florida/4/2006 PV. Pearson's two-tailed analysis performed using GraphPad Prism. Strong correlation is observed between log SRH and HI (Pearsons $r=0.62$. $\log \mathrm{pMN}$ and $\log \mathrm{HI}$ correlate well (Pearsons $r=0.56$ ), and weak correlation was seen between log $\mathrm{pMN}$ and $\log \mathrm{SRH}($ Pearsons $\mathrm{r}=0.30) . p>0.05=\mathrm{ns}, p \leq 0.001={ }^{* * *}, p \leq 0.0001=^{* * * *}$. 


\section{Florida: $\log 10$ V2 (IC90)}

V2: $\log$ pMN vs log HI

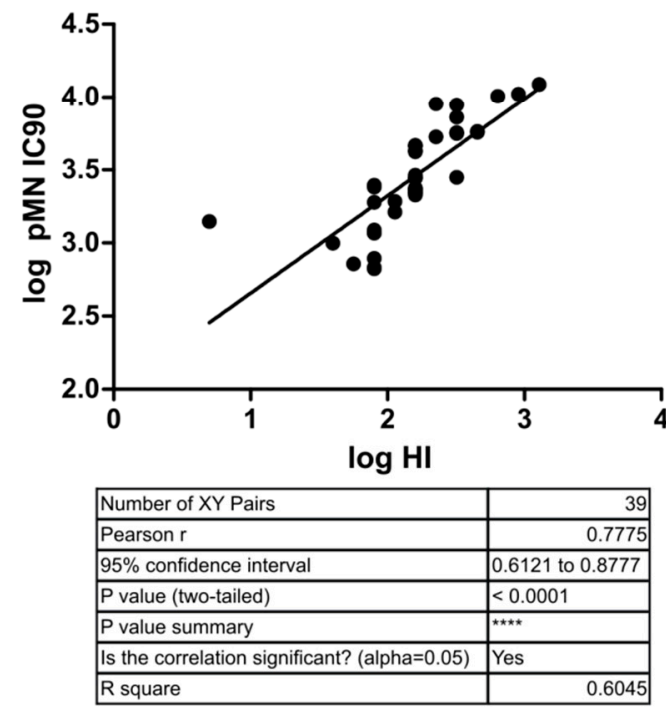

V2: $\log$ pMN vs $\log$ SRH

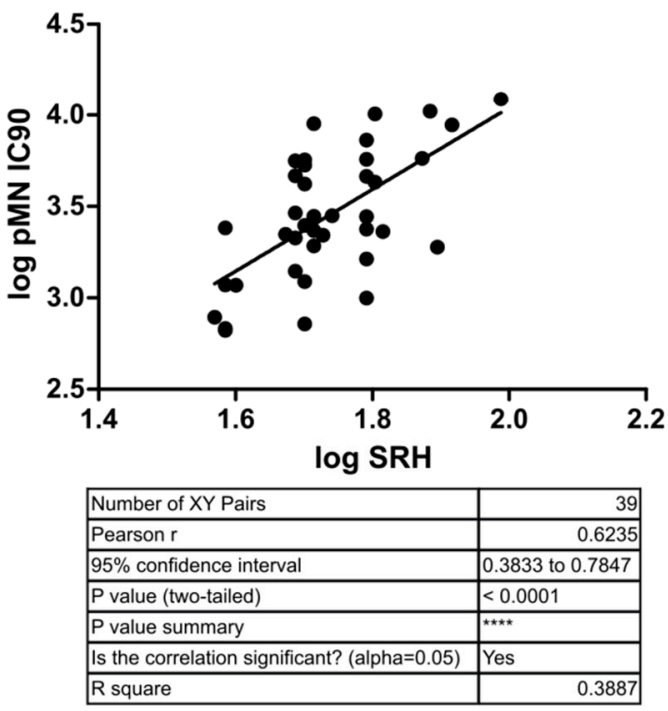

Figure 14. Correlation of transformed $(\log 10)$ data for $\mathrm{pMN}\left(\mathrm{IC}_{90}\right)$ with $\mathrm{SRH}$ and $\mathrm{HI}$ mean V2 values, assayed against B/Florida/4/2006 PV. Pearson's two-tailed analysis performed using GraphPad Prism. Strong correlation was observed between $\log \mathrm{IC}_{90}$ antibody titres and $\log \mathrm{HI}$ or SRH values, with Pearsons $\mathrm{r}$ values of 0.77 and 0.62 , respectively. $p \leq 0.0001={ }^{* * * *}$.

\section{Florida: V2 (IC90)}

\section{V2: pMN vs HI}

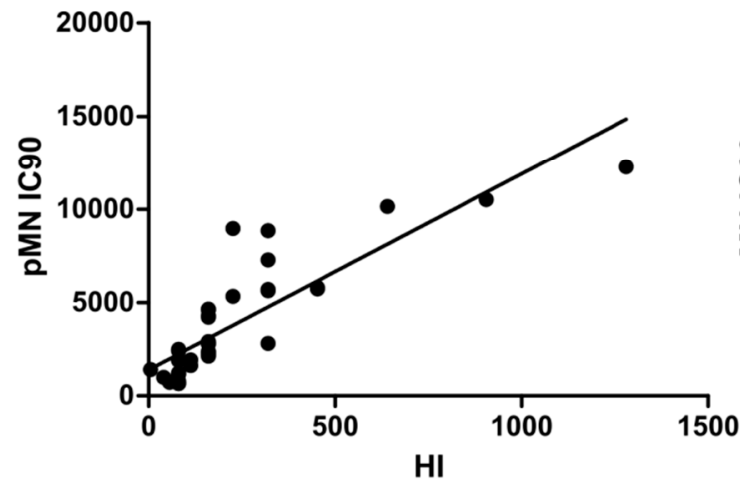

V2: pMN vs SRH

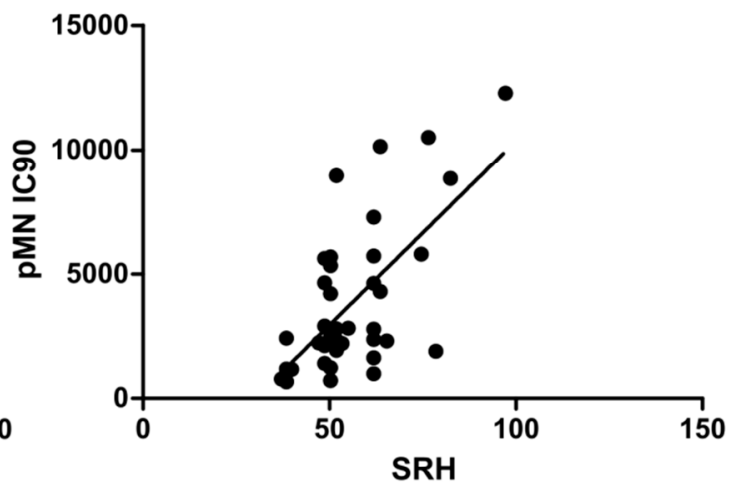

\begin{tabular}{|l|r|}
\hline Number of XY Pairs & 39 \\
\hline Pearson r & 0.6469 \\
\hline $95 \%$ confidence interval & 0.4163 to 0.7993 \\
\hline P value (two-tailed) & $<0.0001$ \\
\hline P value summary & $\star \star \star \star$ \\
\hline Is the correlation significant? (alpha $=0.05)$ & Yes \\
\hline R square & \multicolumn{1}{|c|}{0.4184} \\
\hline
\end{tabular}

Figure 15. Correlation between pMN ( $\left.\mathrm{IC}_{90}\right)$ with $\mathrm{SRH}$ and $\mathrm{HI}$ mean V2 values, assayed against B/Florida/4/2006 PV. Pearson's two-tailed analysis performed using GraphPad prism. Strong correlation was observed between IC 90 antibody titres and $\mathrm{HI}$ or SRH, with Pearsons $\mathrm{r}$ values of 0.85 and 0.64 , respectively. $p \leq 0.0001=^{* * * *}$.

\section{Discussion}

Neutralisation of influenza B bearing PV with influenza B-specific mAbs was consistent, with the exception of B/Brisbane/60/2008 PV. Victoria-lineage-specific mAbs neutralised the type B/Victoria/2/1987 PV, while Yamagata-lineage-specific mAbs neutralised Yamagata 
lineage strains (Figures 1-3). The cross-lineage-specific mAb 2F11 neutralised both lineages as well as the pre-lineage split strain B/Hong Kong/8/1973. Discordant correlation was observed between Victoria and Yamagata lineages, with the former correlating well between pMN, SRH and HI and the latter only correlating, weakly, between SRH and HI.

\subsection{Neutralisation by Influenza $B \mathrm{mAbs}$}

While the majority of influenza B mAbs generated by the FDA neutralised the expected strains in the pMN assay, neutralisation was not seen for B/Brisbane/60/2008 by Victoriaspecific $\mathrm{mAbs}$, in contrast to data supporting the characterisation of these mAbs [40].

One possible explanation for this is N-linked glycosylation masking epitopes on the HA surface. The presence or absence of a glycosylated residue would dramatically affect results when neutralising with a mAb targetting one specific epitope. In this study, a WT B/Brisbane/60/2008 gene was used to produce PV for use in pMN, while B/Victoria/2/1987 was human-codon-optimised. HI and SRH made use of inactivated antigen produced in bacteria, whereas Verma and colleagues used a combination of ELISA using inactivated antigen and PV assays, with the latter using an egg-adapted strain of B/Brisbane/60/2008. Studies on egg-adaptation of influenza B viruses have characterised mutations within the 190 helix loop of the receptor-binding domain, which led to a significant change in antigenicity of the HA $[55,56]$ due to the loss of an N-linked glycosylation site [57]. Despite the lack of neutralisation shown against B/Brisbane/60/2008 by the Victoria-specific mAbs in this study, polyclonal hyperimmune antisera produced against the same HA subtype was the most effective at neutralising it (Figure 4), suggesting that the HA itself is antigenically correct and that the problem lies in the specific epitopes targeted by $8 \mathrm{E} 12$ and $5 \mathrm{~A} 1$. These $\mathrm{mAbs}$ were reported to bind to the amino acid residues 241 and 203, respectively, which are within or close to the 190 helix, which spans from residue 195 to $235[40,58]$.

The fact that $\mathrm{mAbs}$ specific for the Victoria lineage also neutralised the pre-lineage split strain (Figure 1) is not surprising, as fewer structural differences have been reported between these than between the pre-lineage strain and the Yamagata lineage. The positions of escape mutations generated against the Victoria lineage-specific mAbs 8E12 and 5A1 presented in their characterisation were P241Q and K203R, respectively [40]. These are present within the 190 helix (RBD) of Victoria strains, which is very similar in amino acid composition to the 190 helix of the pre lineage split strain B/Hong Kong/8/1973 [58].

\subsection{Correlation between $S R H$ and $H I$}

Overall, SRH and HI correlated strongly across both lineages, except for in V1 samples, which were predictably very low due to the lower sensitivity of these assays. As most of the V1 samples were negative in terms of HI and SRH data, they were clustered around the respective titres of 5 and $4 \mathrm{~mm}^{2}$, which led to a lack of correlation through analysis. Fold change and V2 samples correlated for both Victoria and Yamagata lineages, indicating that increases in influenza B HA-specific antibodies are detected by both assays.

\subsection{Correlation between $p M N$ and $S R H$}

pMN correlated strongly with SRH for the Yamagata lineage strain, with correlation observed for all data sets except for the negative or low titre samples that clustered to the lower detection limit of SRH at $4 \mathrm{~mm}^{2}$. This suggests that pMN would be preferable for the evaluation of low-response samples, as its sensitivity offers an advantage over SRH. For B/Brisbane/60/2008, however, the only correlation observed was between $\mathrm{IC}_{90}$ values (transformed and raw data). Despite this, Pearson's $r$ was still below 0.5 in each case.

\subsection{Correlation between $p M N$ and $H I$}

As with pMN and SRH, a strong correlation is seen for the Yamagata strain (Figures 6-10) but not the Victoria strain (Figures 8-12); once again, B/Brisbane/60/2008 only poorly correlates when analysis is performed using $\mathrm{IC}_{90}$ values (Figure 10). B/Brisbane/60/2008 
$\mathrm{IC}_{50}$ antibody titres do not correlate with SRH or $\mathrm{HI}$ when using either fold-change or V2 data, transformed or raw.

\subsection{Limitations of This Study}

Influenza B viruses have not undergone the ether treatment that could enhance their performance in the HI assay, despite reducing the assay specificity. The pseudotype-based assay represents a novel platform that is increasingly used by laboratories worldwide. However, each assay and antigen requires validation and optimization before this assay can compete with traditional $\mathrm{HI}$ or MN assays, which remain the gold standard for immunological outputs. In addition, as this was a single-cycle assay, the effect of neutralising or interfering antibodies on viral egress was not measured, contrary to live virus assays such as MN or PRNT, where an effect can be measured on viral egress. In our hands, the B/Brisbane/60/2008 PV did not perform as expected against characterised monoclonal antibodies, despite being strongly neutralised by polyclonal serum raised against the same antigen. This was a small panel of mAbs that would benefit from being expanded and evaluated on B/Brisbane/60/2008.

\section{Conclusions}

The results presented in this study, while discordant in regards to B/Brisbane/60/2008 $\mathrm{PV}$, still represent the first comprehensive study correlating HI, SRH and $\mathrm{pMN}$ assays for influenza B serology. Lentiviral pseudotypes are becoming increasingly popular as a surrogate for live virus neutralisation assays-especially in current $R \& D$ using containment level 3 or 4 pathogens such as SARS-CoV-2 and Ebolavirus. The exquisite sensitivity of this assay allows the differentiation of serum samples that would otherwise be categorized as negative in the gold standard assays. This sensitivity can be a double-edged sword, as serum samples and reference antisera against the influenza B lentiviral pseudotypes reported in this study were strongly neutralising, leading to exceptionally high $\mathrm{IC}_{50}$ titers that may have been an overestimation of the serum potency. The nature of each assay described in this study is unique and detects antibodies that may interfere at different points in the virus life cycle. Neutralising antibodies are among the most important and often the goal for universal vaccine approaches-but are not explicitly detected by older assays including SRH and ELISA.

Many efforts have been made to standardise assays between platforms and laboratories to facilitate the comparison of different projects and data sets, such as the efforts by the Consortium for the Standardization of Influenza Seroepidemiology (CONSISE, https:/ / consise.tghn.org/) and the establishment of reference standards and calibrants by the National Institute for Biological Standards and Control (NIBSC, nibsc.org). Until each pseudotyped virus has been fully validated and compared to traditional microneutralisation in a parallel and controlled setting, the gold standard assays will remain preferable for laboratories that are able to perform live virus assays.

Supplementary Materials: The following are available online at https://www.mdpi.com/2076-3 93X/9/2/100/s1, Figure S1: Titration of luciferase pseudotypes bearing the B/Brisbane/60/2008 haemagglutinin on HEK293T/17 cells. Quality control and production optimisation can be found as described previously.

Author Contributions: Conceptualization, G.W.C., C.M.T., F.F., E.M., N.J.T.; methodology, G.W.C., C.M.T., F.F.; validation, G.W.C., C.M.T.; formal analysis, G.W.C., C.M.T.; resources, E.M., N.J.T.; data curation, G.W.C., C.M.T.; writing — original draft preparation, G.W.C., C.M.T.; Writing—review and editing, G.W.C., C.M.T., N.J.T.; supervision, E.M, N.J.T.; funding acquisition, E.M, N.J.T. All authors have read and agreed to the published version of the manuscript.

Funding: This research received no external funding.

Data Availability Statement: The data presented in this study are available on request from the corresponding author. 
Conflicts of Interest: The authors declare no conflict of interest.

\section{References}

1. Hause, B.M.; Collin, E.A.; Liu, R.; Huang, B.; Sheng, Z.; Lu, W.; Wang, D.; Nelson, E.A.; Li, F. Characterization of a novel influenza virus in cattle and swine: Proposal for a new genus in the Orthomyxoviridae family. MBio 2014, 5, 1-10. [CrossRef]

2. Rota, P.A.; Wallis, T.R.; Harmon, M.W.; Rota, J.S.; Kendal, A.P.; Nerome, K. Cocirculation of two distinct evolutionary lineages of influenza type B virus since 1983. Virology 1990, 175, 59-68. [CrossRef]

3. Ambrose, C.S.; Levin, M.J. The rationale for quadrivalent influenza vaccines. Hum. Vaccines Immunother. 2012, 8, 81-88. [CrossRef]

4. Glezen, W.P.; Schmier, J.K.; Kuehn, C.M.; Ryan, K.J.; Oxford, J.S. The burden of influenza B: A structured literature review. Am. J. Public Health 2013, 103, 43-51. [CrossRef] [PubMed]

5. Mccullers, J.A.; Saito, T.; Iverson, A.R. Multiple Genotypes of Influenza B Virus Circulated between 1979 and 2003. J. Virol. 2004, 78, 12817-12828. [CrossRef]

6. Belshe, R.B. The need for quadrivalent vaccine against seasonal influenza. Vaccine 2010, 28, D45-D53. [CrossRef] [PubMed]

7. Heikkinen, T.; Ikonen, N.; Ziegler, T. Impact of influenza B lineage-level mismatch between trivalent seasonal influenza vaccines and circulating viruses, 1999-2012. Clin. Infect. Dis. 2014, 59, 1519-1524. [CrossRef] [PubMed]

8. WHO Weekly epidemiological record: 2016, 88, 73-81. Available online: https://www.who.int/wer/2016/wer9107.pdf?ua=1 (accessed on 10 November 2020).

9. Weir, J.P.; Gruber, M.F. An overview of the regulation of influenza vaccines in the United States. Influenza Other Respir. Viruses 2016, 10, 354-360. [CrossRef]

10. Wood, J.M.; Schild, G.C.; Newman, R.W.; Seagroatt, V. An improved single-radial-immunodiffusion technique for the assay of influenza haemagglutinin antigen: Application for potency determinations of inactivated whole virus and subunit vaccines. J. Biol. Stand. 1977, 5, 237-247. [CrossRef]

11. Cate, T.R.; Couch, R.B.; Parker, D.; Baxter, B. Reactogenicity, immunogenicity, and antibody persistence in adults given inactivated influenza virus vaccines-1978. Rev. Infect. Dis. 1983, 5, 737-747. [CrossRef] [PubMed]

12. Hobson, D.; Curry, R.L.; Beare, A.S.; Ward-Gardner, A.; Refinery, E. The role of serum haemagglutination-inhibiting antibody in protection against challenge infection with influenza A2 and B viruses. J. Hyg. (Lond) 1972, 70, 767-777. [CrossRef] [PubMed]

13. La Montagne, J.R.; Noble, G.R.; Quinnan, G.V.; Curlin, G.T.; Blackwelder, W.C.; Smith, J.I.; Ennis, F.A.; Bozeman, F.M. Summary of clinical trials of inactivated influenza vaccine-1978. Rev. Infect. Dis. 1983, 5, 723-736. [CrossRef] [PubMed]

14. Williams, M.S. Single-radial-immunodiffusion as an in vitro potency assay for human inactivated viral vaccines. Vet. Microbiol. 1993, 37, 253-262. [CrossRef]

15. Williams, M.S.; Mayner, R.E.; Daniel, N.J.; Phelan, M.A.; Rastogi, S.C.; Bozeman, F.M.; Ennis, F.A. New developments in the measurement of the hemagglutinin content of influenza virus vaccines by single-radial-immunodiffusion. J. Biol. Stand. 1980, 8 , 289-296. [CrossRef]

16. Wise, T.G.; Dolin, R.; Mazur, M.H.; Top, F.H.; Edelman, R.; Ennis, F.A. Serologic responses and systemic reactions in adults after vaccination with bivalent $\mathrm{A} /$ victoria/75-A/new jersey/76 and monovalent $\mathrm{B} /$ hong kong/72 influenza vaccines. J. Infect. Dis. 1977, 136, S507-S517. [CrossRef]

17. Wright, P.F.; Cherry, J.D.; Foy, H.M.; Glezen, W.P.; Hall, C.B.; McIntosh, K.; Monto, A.S.; Parrott, R.H.; Portnoy, B.; Taber, L.H. Antigenicity and reactogenicity of influenza A/USSR/77 virus vaccine in children-a multicentered evaluation of dosage and safety. Rev Infect Dis 1983, 5, 758-764. [CrossRef]

18. Hirst, G.K. The agglutination of red cells by allantoic fluid of chick embryos infected with influenza virus. Science (80-) 1941, 94, 22-23. [CrossRef]

19. Lambré, C.R.; Kasturi, K.N. A microplate immunoenzyme assay for anti-influenza antibodies. J. Immunol. Methods 1979, 26 , 61-67. [CrossRef]

20. Schild, G.C.; Pereira, M.S.; Chakraverty, P. Single-radial-hemolysis: A new method for the assay of antibody to influenza haemagglutinin. Applications for diagnosis and seroepidemiologic surveillance of influenza. Bull. World Health Organ. 1975, 52, 43-50.

21. Bodle, J.; Verity, E.E.; Ong, C.; Vandenberg, K.; Shaw, R.; Barr, I.G.; Rockman, S. Development of an enzyme-linked immunoassay for the quantitation of influenza haemagglutinin: An alternative method to single radial immunodiffusion. Influenza Other Respir. Viruses 2013, 7, 191-200. [CrossRef] [PubMed]

22. Estmer Nilsson, C.; Abbas, S.; Bennemo, M.; Larsson, A.; Hämäläinen, M.D.; Frostell-Karlsson, Å. A novel assay for influenza virus quantification using surface plasmon resonance. Vaccine 2010, 28, 759-766. [CrossRef] [PubMed]

23. Hashem, A.M.; Gravel, C.; Farnsworth, A.; Zou, W.; Lemieux, M.; Xu, K.; Li, C.; Wang, J.; Goneau, M.F.; Merziotis, M.; et al. A Novel Synthetic Receptor-Based Immunoassay for Influenza Vaccine Quantification. PLoS ONE 2013, 8, e55428. [CrossRef] [PubMed]

24. Khurana, S.; King, L.R.; Manischewitz, J.; Coyle, E.M.; Golding, H. Novel antibody-independent receptor-binding SPR-based assay for rapid measurement of influenza vaccine potency. Vaccine 2014, 32, 2188-2197. [CrossRef] [PubMed]

25. Kuck, L.R.; Sorensen, M.; Matthews, E.; Srivastava, I.; Cox, M.M.J.; Rowlen, K.L. Titer on chip: New analytical tool for influenza vaccine potency determination. PLoS ONE 2014, 9, e109616. [CrossRef] [PubMed] 
26. Pierce, C.L.; Williams, T.L.; Moura, H.; Pirkle, J.L.; Cox, N.J.; Stevens, J.; Donis, R.O.; Barr, J.R. Quantification of immunoreactive viral influenza proteins by immunoaffinity capture and isotope-dilution liquid chromatography-tandem mass spectrometry. Anal. Chem. 2011, 83, 4729-4737. [CrossRef]

27. Schmeisser, F.; Vasudevan, A.; Soto, J.; Kumar, A.; Williams, O.; Weir, J.P. A monoclonal antibody-based immunoassay for measuring the potency of 2009 pandemic influenza H1N1 vaccines. Influenza Other Respir. Viruses 2014, 8, 587-595. [CrossRef]

28. Temperton, N.J.; Hoschler, K.; Major, D.; Nicolson, C.; Manvell, R.; Hien, V.M.; Ha, D.Q.; de Jong, M.D.; Zambon, M.C.; Takeuchi, Y.; et al. A sensitive retroviral pseudotype assay for influenza H5N1-neutralizing antibodies. Influenza Other Respir. Viruses 2007, 1, 105-112. [CrossRef]

29. Trombetta, C.M.; Perini, D.; Mather, S.T.; Temperton, N.J.; Montomoli, E. Overview of Serological Techniques for Influenza Vaccine Evaluation: Past, Present and Future. Vaccines 2014, 2, 707-734. [CrossRef]

30. Wen, Y.; Han, L.; Palladino, G.; Ferrari, A.; Xie, Y.; Carfi, A.; Dormitzer, P.R.; Settembre, E.C. Conformationally selective biophysical assay for influenza vaccine potency determination. Vaccine 2015, 33, 5342-5349. [CrossRef]

31. Kendal, A.P.; Cate, T.R. Increased sensitivity and reduced specificity of hemagglutination inhibition tests with ether-treated influenza B/Singapore/222/79. J. Clin. Microbiol. 1983, 18, 930-934. [CrossRef] [PubMed]

32. Monto, A.S.; Maassab, H.F. Ether treatment of type B influenza virus antigen for the hemagglutination inhibition test. J. Clin. Microbiol. 1981, 13, 54-57. [CrossRef] [PubMed]

33. Pyhälä, R.; Kleemola, M.; Visakorpi, R. The HI test modified by ether treatment in the sero-epidemiological surveillance of influenza B. J. Hyg. (Lond.) 1985, 94, 341-348. [CrossRef]

34. Chakraverty, P. Comparison of haemagglutination-inhibition and single-radial-haemolysis techniques for detection of antibodies to influenza B virus. Arch. Virol. 1980, 63, 285-289. [CrossRef] [PubMed]

35. Julkunen, I.; Pyhälä, R.; Hovi, T. Enzyme immunoassay, complement fixation and hemagglutination inhibition tests in the diagnosis of influenza A and B virus infections. Purified hemagglutinin in subtype-specific diagnosis. J. Virol. Methods 1985, 10, 75-84. [CrossRef]

36. Oxford, J.S.; Yetts, R.; Schild, G.C. Quantitation and analysis of the specificity of post-immunization antibodies to influenza B viruses using single radial haemolysis. J. Hyg. 1982, 88, 325-333. [CrossRef]

37. Turner, R.; Lathey, J.L.; Van Voris, L.P.; Belshe, R.B. Serological diagnosis of influenza B virus infection: Comparison of an enzyme-linked immunosorbent assay and the hemagglutination inhibition test. J. Clin. Microbiol 1982, 15, 824-829. [CrossRef]

38. Prevail, T.; Writing, I.I.; Ii, M.P.; Team, S.; Richard, T.; Davey, J.; Dodd, L.; Proschan, M.A.; Neaton, J.; Nordwall, J.N.; et al. A Randomized, Controlled Trial of ZMapp for Ebola Virus Infection. N. Engl. J. Med. 2016, 375, 1448-1456. [CrossRef]

39. Qiu, X.; Wong, G.; Audet, J.; Bello, A.; Fernando, L.; Alimonti, J.B.; Fausther-Bovendo, H.; Wei, H.; Aviles, J.; Hiatt, E.; et al. Reversion of advanced Ebola virus disease in nonhuman primates with ZMapp. Nature 2014, 514, 47-53. [CrossRef]

40. Verma, S.; Soto, J.; Vasudevan, A.; Schmeisser, F.; Alvarado-Facundo, E.; Wang, W.; Weiss, C.D.; Weir, J.P. Determination of influenza B identity and potency in quadrivalent inactivated influenza vaccines using lineage-specific monoclonal antibodies. PLoS ONE 2017, 12, e0175733. [CrossRef]

41. Hai, R.; Krammer, F.; Tan, G.S.; Pica, N.; Eggink, D.; Maamary, J.; Margine, I.; Albrecht, R.A.; Palese, P. Influenza Viruses Expressing Chimeric Hemagglutinins: Globular Head and Stalk Domains Derived from Different Subtypes. J. Virol. 2012, 86, 5774-5781. [CrossRef] [PubMed]

42. Al-Khayatt, R.; Jennings, R.; Potter, C.W. Interpretation of responses and protective levels of antibody against attenuated influenza A viruses using single radial haemolysis. J. Hyg. (Lond.) 1984, 93, 301-312. [CrossRef] [PubMed]

43. Cox, R.J. Correlates of protection to influenza virus, where do we go from here? Hum. Vaccin. Immunother. 2013, 9, 405-408. [CrossRef] [PubMed]

44. Potter, C.W.; Oxford, J.S. Determinants of immunity to influenza infection in man. Br. Med. Bull. 1979, 35, 69-75. [CrossRef]

45. Wood, J.M.; Gaines-Das, R.E.; Taylor, J.; Chakraverty, P. Comparison of influenza serological techniques by international collaborative study. Vaccine 1994, 12, 167-174. [CrossRef]

46. Trombetta, C.M.; Remarque, E.J.; Mortier, D.; Montomoli, E. Comparison of hemagglutination inhibition, single radial hemolysis, virus neutralization assays, and ELISA to detect antibody levels against seasonal influenza viruses. Influenza Other Respir. Viruses 2018, 12, 675-686. [CrossRef]

47. Demaison, C.; Parsley, K.; Brouns, G.; Scherr, M.; Battmer, K.; Kinnon, C.; Grez, M.; Thrasher, A.J. High-level transduction and gene expression in hematopoietic repopulating cells using a human immunodeficiency [correction of imunodeficiency] virus type 1-based lentiviral vector containing an internal spleen focus forming virus promoter. Hum. Gene Ther. 2002, 13, 803-813. [CrossRef]

48. Zufferey, R.; Dull, T.; Mandel, R.J.; Bukovsky, A.; Quiroz, D.; Naldini, L.; Trono, D. Self-inactivating lentivirus vector for safe and efficient in vivo gene delivery. J. Virol. 1998, 72, 9873-9880. [CrossRef]

49. Jung, H.; Lee, K.P.; Park, S.J.; Park, J.H.; Jang, Y.S.; Choi, S.Y.; Jung, J.G.; Jo, K.; Park, D.Y.; Yoon, J.H.; et al. TMPRSS4 promotes invasion, migration and metastasis of human tumor cells by facilitating an epithelial-mesenchymal transition. Oncogene 2008, 27, 2635-2647. [CrossRef]

50. Böttcher-Friebertshäuser, E.; Klenk, H.-D.; Garten, W. Activation of influenza viruses by proteases from host cells and bacteria in the human airway epithelium. Pathog. Dis. 2013, 69, 87-100. [CrossRef] 
51. Böttcher-Friebertshäuser, E.; Matrosovich, T.Y.; Beyerle, M.; Klenk, H.-D.; Garten, W.; Matrosovich, M.N. Proteolytic activation of influenza viruses by serine proteases TMPRSS2 and HAT from human airway epithelium. J. Virol. 2006, 80, 9896-9898. [CrossRef] [PubMed]

52. Böttcher-Friebertshäuser, E.; Freuer, C.; Steinmetzer, T.; Klenk, H.-D.; Garten, W. MDCK cells that express proteases TMPRSS2 and HAT provide a cell system to propagate influenza viruses in the absence of trypsin and to study cleavage of HA and its inhibition. Vaccine 2009, 27, 6324-6329. [CrossRef] [PubMed]

53. Trombetta, C.M.; Perini, D.; Vitale, L.; Cox, R.J.; Stanzani, V.; Piccirella, S.; Montomoli, E. Validation of Single Radial Haemolysis assay: A reliable method to measure antibodies against influenza viruses. J. Immunol. Methods 2015, 422, 95-101. [CrossRef] [PubMed]

54. Ferrara, F.; Carnell, G.; Kinsley, R.; Böttcher-Friebertshäuser, E.; Pöhlmann, S.; Scott, S.; Fereidouni, S.; Corti, D.; Kellam, P.; Gilbert, S.C.; et al. Development and use of lentiviral vectors pseudotyped with influenza B haemagglutinins: Application to vaccine immunogenicity, mAb potency and sero-surveillance studies. BioRxiv 2018. [CrossRef]

55. Robertson, J.S.; Naeve, C.W.; Webster, R.G.; Bootman, J.S.; Newman, R.W.; Schild, G.C. Alterations in the hemagglutinin associated with adaptation of influenza B virus to growth in eggs. Virology 1985, 143, 166-174. [CrossRef]

56. Shaw, M.W.; Xu, X.; Li, Y.; Normand, S.; Ueki, R.T.; Kunimoto, G.Y.; Hall, H.; Klimov, A.; Cox, N.J.; Subbarao, K. Reappearance and Global Spread of Variants of Influenza B/Victoria/2/87 Lineage Viruses in the 2000-2001 and 2001-2002 Seasons. Virology 2002. [CrossRef]

57. Saito, T.; Nakaya, Y.; Suzuki, T.; Ito, R.; Saito, T.; Saito, H.; Takao, S.; Sahara, K.; Odagiri, T.; Murata, T.; et al. Antigenic alteration of influenza B virus associated with loss of a glycosylation site due to host-cell adaptation. J. Med. Virol. 2004, 74, 336-343. [CrossRef]

58. Ni, F.; Kondrashkina, E.; Wang, Q. Structural basis for the divergent evolution of influenza B virus hemagglutinin. Virology 2013, 446, 112-122. [CrossRef] 